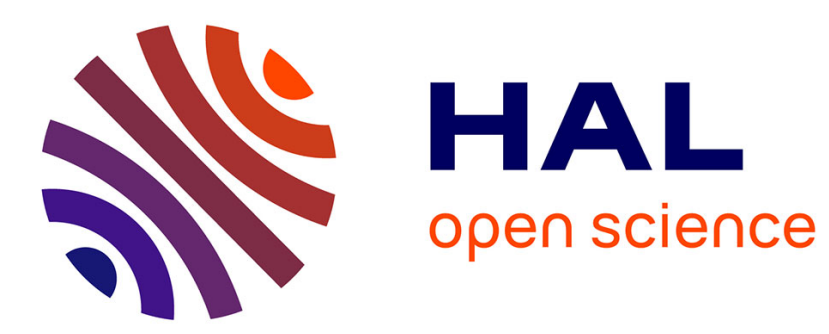

\title{
Model and Measure of Flows at the Intake of Engines
}

\author{
L. Le Moyne, F. Maroteaux, Philippe Guibert, M. Murat
}

\section{To cite this version:}

L. Le Moyne, F. Maroteaux, Philippe Guibert, M. Murat. Model and Measure of Flows at the Intake of Engines. Journal de Physique III, 1997, 7 (10), pp.1927-1940. 10.1051/jp3:1997101 . jpa-00249691

\section{HAL Id: jpa-00249691 https://hal.science/jpa-00249691}

Submitted on 1 Jan 1997

HAL is a multi-disciplinary open access archive for the deposit and dissemination of scientific research documents, whether they are published or not. The documents may come from teaching and research institutions in France or abroad, or from public or private research centers.
L'archive ouverte pluridisciplinaire HAL, est destinée au dépôt et à la diffusion de documents scientifiques de niveau recherche, publiés ou non, émanant des établissements d'enseignement et de recherche français ou étrangers, des laboratoires publics ou privés. 


\title{
Model and Measure of Flows at the Intake of Engines
}

\author{
L. Le Moyne $\left({ }^{*}\right)$, F. Maroteaux, P. Guibert and M. Murat \\ Laboratoire de Mécanique Physique, Université Pierre et Marie Curie, \\ 2 place de la gare de centure, 78210 St Cyr l'École, France
}

(Received 10 March 1997, revised 4 June 1997, accepted 23 June 1997)

PACS.47.55.Kf - Multiphase and particle-laden flows

PACS 47.55.Dz - Drops and bubbles

PACS.47.80.+v - Instrumentation for fluid dynamics

\begin{abstract}
A simple physical model is developed to simulate the annular dispersed multiphase flow observed at the intake of spark ignition port-mjected engines. The model is a separate phase 2D model taking into account gas, droplets and liquid film phases. It is validated by the results of different measurements made on engine. Temperature, pressure and velocity measurements are made in the intake manifold of a production engine in order to characterize the flows of gaseous phases. Velocity measurements are also made for injected fuel droplets. Global equivalence ratio measurements are made to validate modeling of deposited fuel film on manifold walls.
\end{abstract}

\section{Symbols}

$C_{\mathrm{p}} \quad$ : specific heat

d : diameter

$E \quad$ : deposited mass flow rate

e : thickness

$\Phi$ : convection heat flux

$\phi \quad$ : convection heat flux density

$f \quad$ : friction coefficient

$F \quad:$ drag force

$g$ : gravity

$\Gamma \quad$ : evaporated mass flow rate

$\gamma \quad$ : ratio of specific heats

$h \quad$ : Thermal exchange coefficient

$\lambda$ : Thermal Conductivity

$L \quad$ : Latent vaporization heat

$$
\begin{array}{ll}
m & : \text { mass } \\
P & : \text { pressure } \\
\theta & : \text { wetted surface angle } \\
q & : \text { mass flow rate } \\
R & : \text { ideal gas constant } \\
\rho & : \text { density } \\
r & : \text { radial coordinate } \\
s & : \text { section area } \\
T & : \text { temperature } \\
t & : \text { time } \\
V & : \text { volume } \\
v, u & : \text { speed } \\
z & : \text { axial coordinate }
\end{array}
$$

$\left.{ }^{*}\right)$ Author for correspondence (e-mail: lemoyne@ccr.jussieu fr) 


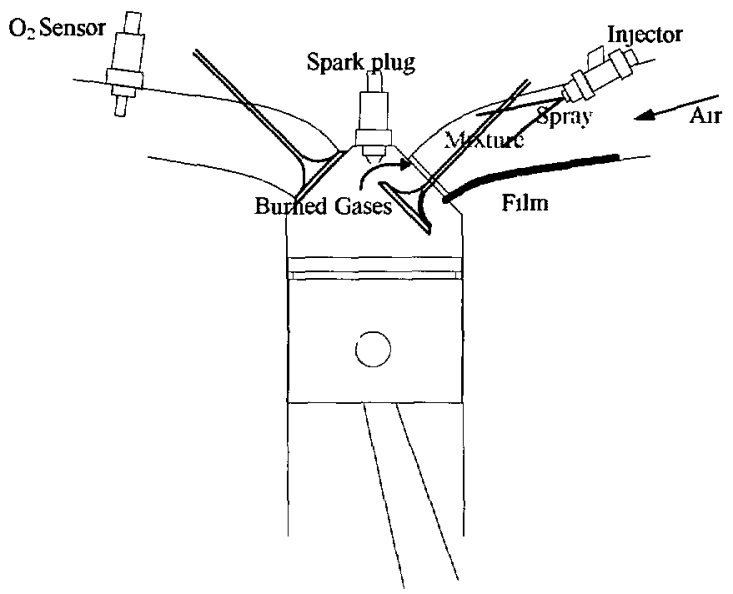

Fig. 1. - Engine arrangement

\section{Subscripts}

$\begin{array}{llll}\mathrm{b} & \text { : burned gases } & \mathrm{m} & \text { : air-fuel mixture } \\ \mathrm{c} & \cdot \text { cylinder } & \mathrm{p} & \text { : manifold walls } \\ \text { eff } & \text { : effective } & \mathrm{s} & : \text { Valve } \\ \mathrm{f} & \text { : film } & \mathrm{t} & : \text { Manifold } \\ \mathrm{g} & \cdot \text { droplet } & & \end{array}$

\section{Introduction}

A very accurate control of air-fuel ratio is required in internal combustion port-injected spark ignition engines in order to comply with pollutant emission standards. Indeed, three-way catalytic converters installed on unleaded fuel engines, function within a very thin margin of pollutants concentration corresponding to stoichiometry conditions. During transients, particularly for cold-engine conditions, the deposited fuel film on manifold and valves induces a delayed response of equivalence ratio (fuel/air mass ratio) between the desired mixture ratio and the real ratio in the cylinder. It results on an important increase of emitted pollutants

The fuel mass inducted in the cylinder must therefore be precisely controlled, and difficulties arise due to the complexity of phenomena taking place in the inlet port during transient operation (acceleration, deceleration) and because response times for each mixture phase are different. These phases are fuel droplets emitted by the injector, air admitted in the intake manifold, hot burned gases flowing back into the manifold from the cylinder, fuel vapor and liquid fuel film deposited on walls. They have been put into evidence by several authors such as Aquino [1] but no physical description that can be successfully applied to engine control has yet been done.

Figure 1 shows the general arrangement of a port-injected engine. The exhaust pipe is represented on the left, fitted with an universal oxygen sensor allowing to measure mixture's equivalence ratio. This type of sensor has been described by Sasayama [2]. The intake manifold where mixture takes place is represented on the right, with the fuel injector targeted on the intake valves. 
We have developed a physical model taking into account the evolution of each phase and their exchanges. The aim of such a model is to perform a physical description of mixture formation, simple enough to be applied to testing and developing control strategies on real engines. We describe here this model applied to the real geometry of a port-injected production engine. We present then the main characteristics of the modeled flows and the results of measurements made on real engine. Finally we discuss the results obtained, the validity of modeling, and future work.

\section{Model}

The flow at the intake is annular multiphase with a dispersed phase (fuel droplets). The model we have developed considers separated phases and is based on the balance equations relative to mass, momentum and energy. The equations are considered on a symmetry plan containing the centers of the injector and the valve.

First, the gas flow is modeled monodimensionaly. At the intake valve opening the manifold pressure is lower than that in the cylinder. It results on a back flow of burned gases from the cylinder to the intake pipe.

Assuming this flow is isentropic, the mass flow rate can be written as:

$$
\begin{aligned}
& \text { if } \frac{P_{\mathrm{t}}}{P_{\mathrm{c}}} \leq\left(\frac{2}{\gamma+1}\right)^{\gamma /(\gamma-1)} \\
& q_{\mathrm{s}}=s_{\mathrm{eff}} \frac{P_{\mathrm{c}}}{\sqrt{R T_{\mathrm{c}}}}\left(\frac{P_{\mathrm{m}}}{P_{\mathrm{c}}}\right)^{1 / \gamma} \sqrt{\frac{2 \gamma}{\gamma-1}\left(1-\left(\frac{P_{\mathrm{m}}}{P_{\mathrm{c}}}\right)^{(\gamma-1) / \gamma}\right)} \\
& \text { if } \frac{P_{\mathrm{t}}}{P_{\mathrm{c}}}>\left(\frac{2}{\gamma+1}\right)^{\gamma /(\gamma-1)} \\
& q_{\mathrm{s}}=s_{\mathrm{eff}} \frac{P_{\mathrm{c}}}{\sqrt{R T_{\mathrm{c}}}} \sqrt{\gamma}\left(\frac{2}{\gamma+1}\right)^{(\gamma+1) / 2(\gamma-1)}
\end{aligned}
$$

$s_{\text {eff }}$ is the effective area at the valve (see Ref. [3]).

Mass variation in the cylinder equals the back flow rate $-q_{\mathrm{s}}$ (exhaust valves are closed). The back flow of hot burned gases pushes (without mixing) the fresh air-fuel mixture towards the intake. Burned gases cool down as they flow into the manifold. Their flow is described by balance equations:

$$
\begin{aligned}
& \frac{\partial \rho_{\mathrm{b}}}{\partial t}+\frac{\partial \rho_{\mathrm{b}} u_{\mathrm{b}}}{\partial z}=0 \\
& \frac{\partial \rho_{\mathrm{b}} u_{\mathrm{b}}}{\partial t}+u_{\mathrm{b}} \frac{\partial \rho_{\mathrm{b}} u_{\mathrm{b}}}{\partial z}=\frac{\rho_{\mathrm{b}} f_{\mathrm{pb}} u_{\mathrm{b}}^{2}}{\mathrm{~d}} \\
& \frac{\partial \rho_{\mathrm{b}} T_{\mathrm{b}}}{\partial t}+u_{\mathrm{b}} \frac{\partial \rho_{\mathrm{b}} T_{\mathrm{b}}}{\partial z}=\frac{h}{C_{\mathrm{p}_{\mathrm{b}}} \frac{\mathrm{d}}{2}}\left(T_{\mathrm{b}}-T_{\mathrm{m}}\right)
\end{aligned}
$$

Boundary conditions at the valve are deduced from the mass flow rate $q_{\mathrm{s}}$ for velocity, and cylinder conditions for temperature and pressure. On the other side, at injector position, boundary conditions are fresh mixture properties. Cylinder and fresh air conditions (temperature and pressure) are obtained from measurements on real engine (typical values are: for cylinder $1150 \mathrm{mbar}, 750 \mathrm{~K}$; for fresh air $600 \mathrm{mbar}, 310 \mathrm{~K}$ ). 
When cylinder pressure equals the manifold pressure, mass flow rate $q_{\mathrm{s}}$ equals zero. The intake flow rate of fresh gases is then set and flow is inverted. Writing the conservation of mass leads to:

$$
\rho_{\mathrm{m}} s_{\mathrm{t}} v_{\mathrm{m}}=c_{\mathrm{s}} \rho_{\mathrm{c}} \frac{\mathrm{d} V_{\mathrm{c}}}{\mathrm{d} t} .
$$

We consider here that a homogeneous turbulent flow is quickly set (Reynolds number reaches 8000 for a velocity of only $5 \mathrm{~m} \mathrm{~s}^{-1}$ ), therefore the velocity distribution over a cross section of the manifold $s_{\mathrm{t}}$ is uniform and equal to $v_{\mathrm{m}}$.

Flow rate coefficient at the valve $c_{\mathrm{s}}$ is set to 0.7 (see Heywood [3]). We consider air-fuel mixture temperature is not affected by other phases (droplets, film and burned gases) and equal to the mean temperature during engine cycle.

Having speed and temperature for gaseous phases at each section of the manifold and time during the engine cycle, we model the injected droplets in a bidimensional statistical lagrangian way. Governing balance equations for single droplets are:

$$
\begin{aligned}
& \frac{\mathrm{d} m_{\mathrm{g}}}{\mathrm{d} t}=-\Gamma_{\mathrm{gm}} \\
& \frac{\mathrm{d} m_{\mathrm{g}} \mathbf{u}_{\mathrm{g}}}{\mathrm{d} t}=-\mathbf{F}_{\mathrm{g}}+\mathrm{m}_{\mathrm{g}} \mathbf{g} \\
& \frac{\mathrm{d} m_{\mathrm{g}} T_{\mathrm{g}}}{\mathrm{d} t}=\frac{1}{C_{\mathrm{p}_{\mathrm{g}}}}\left(\Phi_{\mathrm{mg}}-\Gamma_{\mathrm{gm}} L_{\mathrm{g}}\right) .
\end{aligned}
$$

So, for each considered droplet we calculate its trajectory until it reaches the manifold walls or the valve, enters into the cylinder, or vaporizes completely. Secondary atomization and coalescence are neglected and deposited droplets are supposed to form a liquid film

To represent all the atomized fuel, we consider different classes of droplets. These droplets are supposed to be created by a stochastic phenomena, pulverization, whose statistical distributions are given by experiments (see [4] and [5]). To calculate the final balance we associate to each class of droplets a weight in the given distribution. So, several instant emissions are taken into account to represent the injection period and several initial directions and diameters are taken into account to represent the injection spray.

Having the position and the impact time of droplets, we calculate the flow of the created fuel film. The film model is bidimensional, balance equations can be written as:

$$
\begin{aligned}
& \frac{\partial e_{\mathrm{f}}}{\partial t}+\frac{\partial e_{\mathrm{f}} u_{\mathrm{f}} \theta}{\theta \partial z}=\frac{1}{\rho_{\mathrm{f}}}\left(E_{\mathrm{gf}}-\Gamma_{\mathrm{fm}}\right) \\
& \frac{\partial u_{\mathrm{f}}}{\partial t}=v_{\mathrm{f}} \frac{\partial^{2} u_{\mathrm{f}}}{\partial r^{2}}+g \cos \gamma \\
& \frac{\partial T_{\mathrm{f}}}{\partial t}=\frac{\lambda_{\mathrm{f}}}{\rho_{\mathrm{f}} C_{\mathrm{p}_{\mathrm{f}}}} \frac{\partial^{2} T_{\mathrm{f}}}{\partial r^{2}} .
\end{aligned}
$$

Mass balance results here on the film thickness governing equation. Wetted surface angle $\theta$ is a given parameter.

Boundary conditions are:

$$
\begin{aligned}
& \text { at the wall: }\left\{\begin{array}{l}
u_{\mathrm{f}}=0 \\
T_{\mathrm{f}}=T_{\mathrm{p}}
\end{array}\right. \\
& \text { on surface: }\left\{\begin{array}{l}
\mu_{\mathrm{f}} \frac{\partial u_{\mathrm{f}}}{\partial r}=\frac{\rho_{\mathrm{m}} f_{\mathrm{mf}} u_{\mathrm{m}}^{2}}{2} \\
\lambda_{\mathrm{f}} \frac{\partial T_{\mathrm{f}}}{\partial r}=\varphi_{\mathrm{mf}}-\Gamma_{\mathrm{fm}} \dot{L}_{\mathrm{f}} .
\end{array}\right.
\end{aligned}
$$


For the numerical solution of film equations, a spectral method is applied to momentum equation and a Cranck-Nicholson scheme is applied to thickness and temperature equations.

Film shape in steady state is obtained after several engine cycles. To obtain it, the above equations must be solved every degree crank angle (720 per cycle) for each cycle until stability is reached. In the same way, in order to simulate engine transients, several hundred cycles must be calculated. This shows the advantage of a model that can be solved quickly when dealing with engine simulation (a real transient can be simulated in less than three hours on a PC).

\section{Results}

Model gives the values of mass, velocity and temperature for each phase. In this section we show some of this results, model being applied to a production engine geometry in the following conditions:

- Manifold Pressure: 300 mbar

- Engine speed: $1400 \mathrm{rpm}$

- Coolant Temperature (wall temperature): $40{ }^{\circ} \mathrm{C}$

- Valve surface temperature. $300^{\circ} \mathrm{C}$

Figure 2 shows at the position corresponding to the measuring access described later (see next section), the velocity of gas predicted by the model. It can be seen that velocity is zero whle intake valve is closed. At its opening $(250 \mathrm{CA})$, the burned gases flow into the intake with negative velocities, then, velocities are inverted and the fresh mixture is admitted until the closure of intake valve $(510 \mathrm{CA})$.

Figure 3 shows the position of modeled droplets in the same conditions. The axis range has been kept to represent a full engine cycle $(720 \mathrm{CA})$. Fuel injection starts $80 \mathrm{CA}$ before intake valve opening and ends $25 \mathrm{CA}$ before valve opening. It can be seen that maximal droplet velocity is $20 \mathrm{~ms}^{-1}$ and droplets are slowed down by drag force.

At the valve opening, droplets are rejected backwards by back flow (negative velocities) and then, dragged into the cylinder when flow inverts. When gas velocity is maximal, there are no more fuel droplets passing through the observed section. Fuel droplets are present during a short period of time during engine cycle.

Figure 4 shows the film thickness on the walls as predicted by the model. It can be seen that deposited fuel is concentrated close to the valve, but there is deposited fuel close to the injector, quite distant from valve. For the considered temperature, film does not vaporize completely. Figure 5 shows mean velocity of fuel film on the walls. The velocity of farthest and thinnest parts of film is quite low, which will result on a slow response of the film.

Concerning temperature, the model assumes hot and fresh gases do not mix. This results on a very simple evolution of temperature, increasing when hot gases are present and decreasing when fresh gases come back. Maximum gas temperature in the intake can reach $400 \mathrm{~K}$ for the above conditions and is certainly over-estimated. Droplet's temperature decreases quite fast until it reaches the temperature of surrounding gases. The back flow of hot gases does not last very long, so it has little influence on the thermal behavior of droplets. Film is generally very thin and so, its temperature is generally almost equal to wall temperature. 


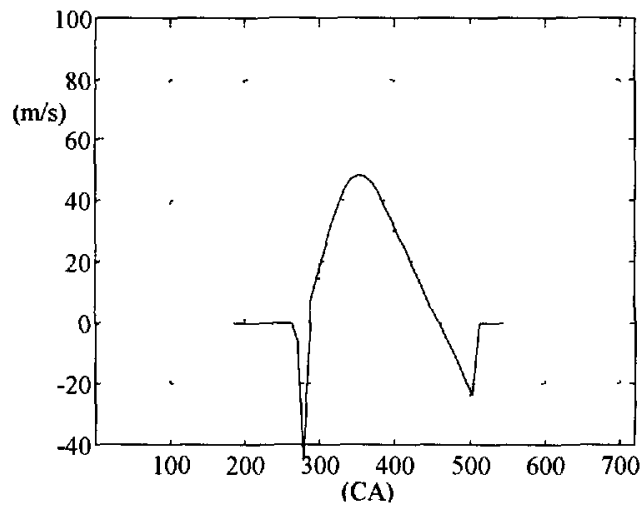

Fig. 2. - Predicted gas velocity versus time during the cycle in the measurement section.

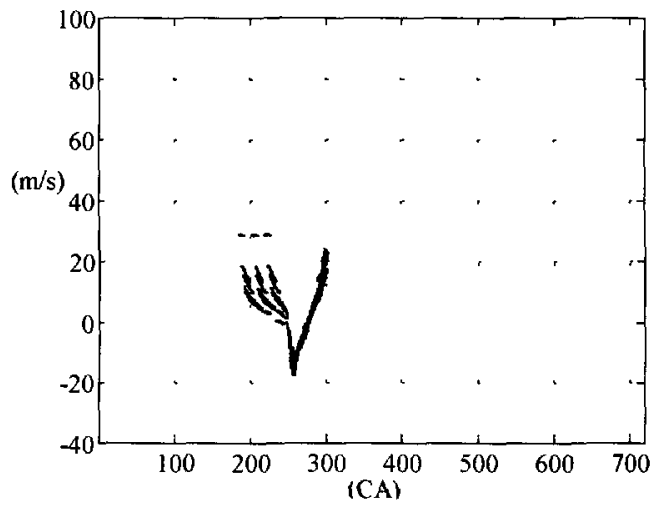

Fig. 3. - Predicted droplets velocity versus time during the cycle in the measurement section

\section{Experiments}

In order to validate the model results for different flows at the intake of the engine, we have done several local measurements on real engine concerning gaseous phase and droplets. Measurements were not made on deposited fuel film because there is presently no way to measure its thickness or velocity in a real engine without considerably changing its characteristics.

We have drilled an orifice in the manifold walls, $5 \mathrm{~cm}$ away from the valve, midway between injector and valve, in order to install different sensors. Figure 6 shows this access position.

The first measurements we present concern the gaseous phase temperature and pressure. We have installed in the measurement access linear thermocouples of diameters $100 \mu \mathrm{m}, 50 \mu \mathrm{m}$ and $25 \mu \mathrm{m}$. We obtained a stabilization of thermocouples response for diameters $50 \mu \mathrm{m}$ and $25 \mu \mathrm{m}$. We also installed a strain gauge pressure transducer. Figure 7 shows the temperature measured by the $25 \mu \mathrm{m}$ thermocouples without compensation of gas velocity, during an engine cycle for three different loads and constant engine speed (1400 rpm). We have produced also the corresponding pressure signals and valve lift. It can be seen that temperature rises most at low load when pressure difference (and back flow) between cylinder and intake manifold are important. The increase of temperature occurs just after the intake valve opening. It is followed by a temperature decrease corresponding to the fresh gases induction. Finally, 


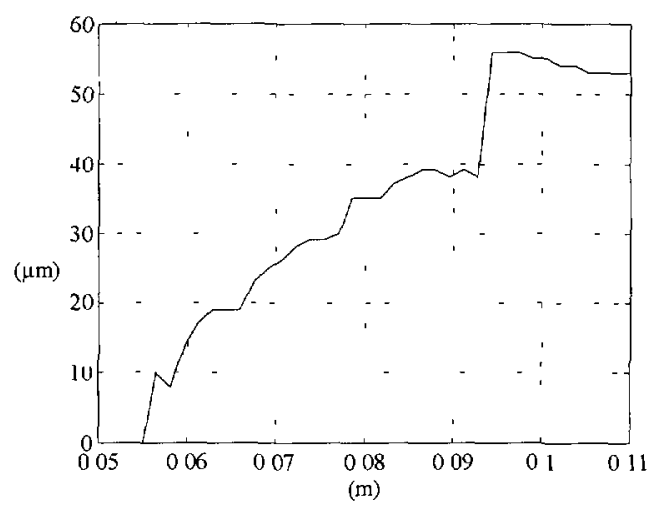

Fig. 4 - Predicted film profile, thickness versus distance from injector (valve is at $0.11 \mathrm{~m}$ ).

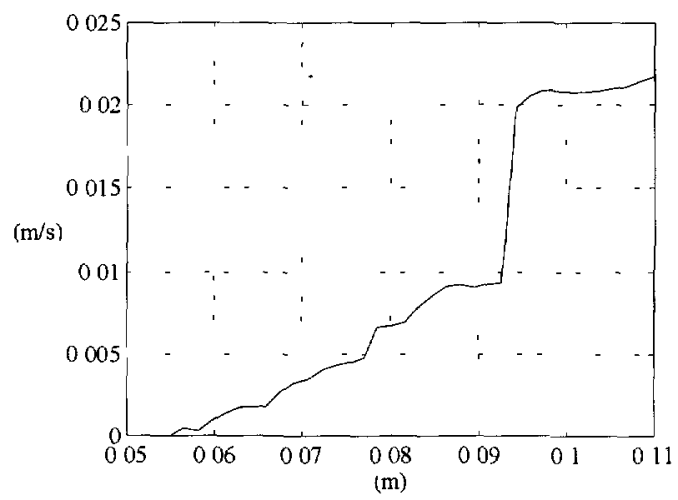

Fig. 5. - - Predicted film velocity versus distance from injector (valve is at $0.11 \mathrm{~m}$ )

temperature stabilizes when valve closes. These results show that in the observed section, temperature changes result from the flow of hot burned gases in the intake. It shows also that mean temperature during engine cycle decreases with load because the injected and deposited fuel mass and air density increase.

The second measurement series consisted on measuring particle velocities in flow. In the measurement access we installed a quartz porthole allowing to use a LDA probe.

First, we have eliminated fuel injection on the intake while maintaining the engine speed. We fed the intake air with fine particles of oil $(\sim 5 \mu \mathrm{m}$ diameter $)$. This particles follow quite well the gas flow, leading to the gas velocity in the observed section. Figure 8 shows the particles velocity as a function of time (crank angle degrees). A gray level is associated to the logarithm of the number of validated particles, which allows to see when, during the engine cycle, most of the particles could be observed. Velocity range was limited to -40 to $100 \mathrm{~m} \mathrm{~s}^{-1}$ in order to obtain good sensitivity. It can be seen that there is a period at the intake valve opening. when particles have negative velocities, corresponding to back flow. It is followed by the period of intake flow when velocities are positive. Otherwise, when intake valve is closed particle velocities are almost zero. It can be seen that acoustical phenomena create important oscillations of speed. This phenomena can not be taken into account by the model. Figure 9 

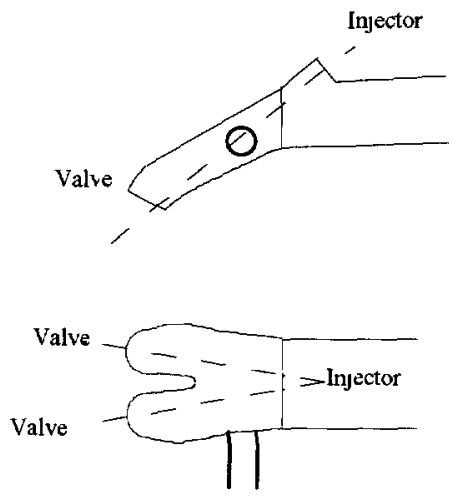

Fig. 6. - Intake with measurement access

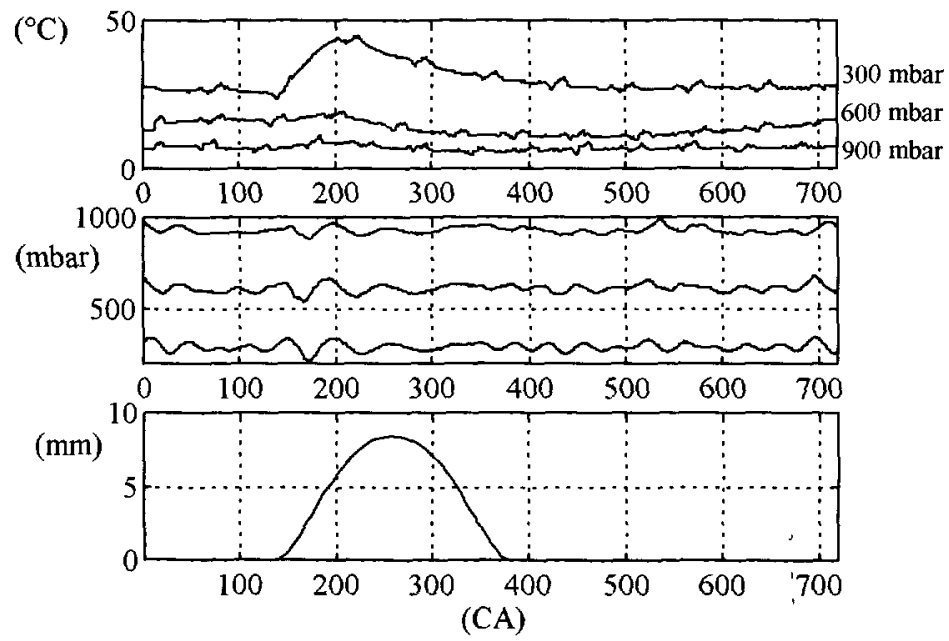

Fig. 7 - Temperature, pressure and valve lift for three loads at constant engine speed (1400 rpm).

and Figure 10 show the same measurements for increasing manifold pressures (engine speed is kept constant). It shows that there are no validated particles outside the invertıng velocities period. This is due to optical access fouling before the amount of validated particles in that period is significant. On Figure 11, the contours of above graphs show that the negative velocity period gets shorter as engine load increases.

Next, we have reestablished fuel injection and eliminated particle feeding. The majority of observed particles are then injected fuel droplets, whose diameters vary between $5 \mu \mathrm{m}$ and $300 \mu \mathrm{m}$ for this kind of injector. Figure 12, Figure 13, and Figure 14 show the results of the measurements for three different loads and constant engine speed. Injection takes place so that it ends 60 degrees crank angle before intake valve opening. The first particles appear at the injection, when valve is closed. Maximal speed of this particles is about $20 \mathrm{~ms}^{-1}$ and corresponds to the initial velocity of injected droplets. Some particles are slowed down. Then, at the intake valve opening the back flow pushes them backwards (negative speed). Finally, the flow change pushes the remaining particles towards the cylinder It can be seen that there 


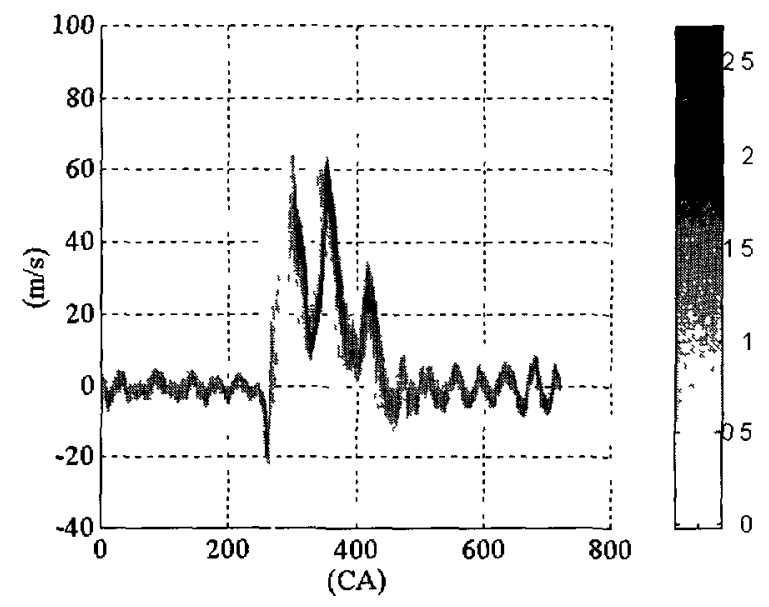

Fig. 8. - Velocity of gas flow - (Log of the number of valıdated particles without injection, 300 mbar, $25 \%$ load, $1400 \mathrm{rpm})$.

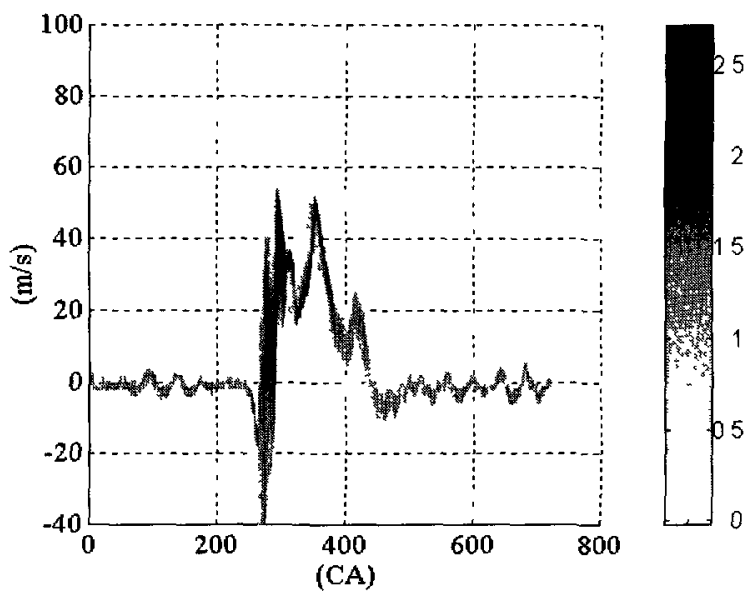

Fig. 9. - Velocity of gas flow - (Log of the number of valıdated particles without injection, 600 mbar, $50 \%$ load, $1400 \mathrm{rpm})$.

are almost no particles validated after the intake flow. The importance of back flow is reduced with load. The amount of fuel (fixed by the injection time) increases with load.

Figure 15 and Figure 16 show the comparison of measurements contours and model results concerning velocities of gases and droplets. It can be seen that model reproduces the mean evolution of velocities, but should be completed in order to reproduce reality with more details.

\section{Global Measurement}

In order to put unto evidence the deposited film and characterize its flow, we have measured the equivalence ratio in the exhaust of the engine with an oxygen sensor. As shown previously, the quick-response phases, gases and droplets, enter the cylinder during the engine cycle. This 


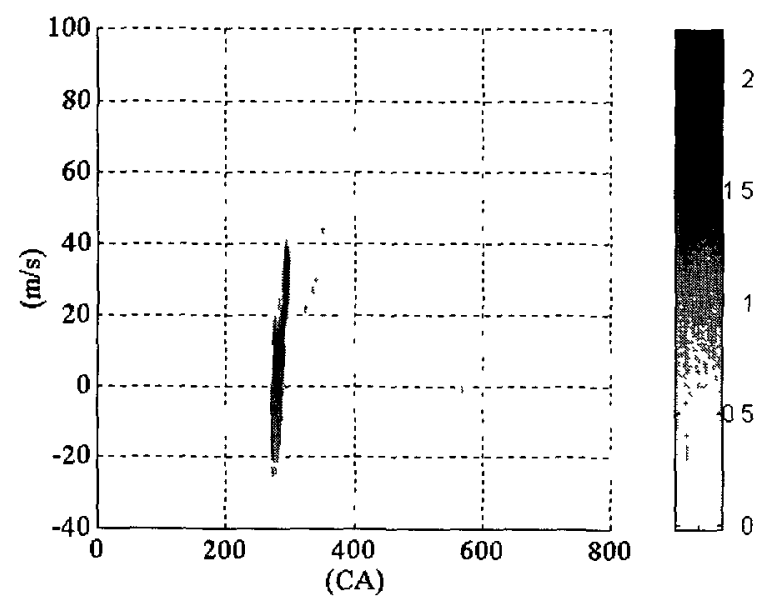

Fig. 10. - Velocity of gas flow - (Log of the number of valıdated particles without injection, $900 \mathrm{mbar}$, $85 \%$ load, $1400 \mathrm{rpm}$ ).

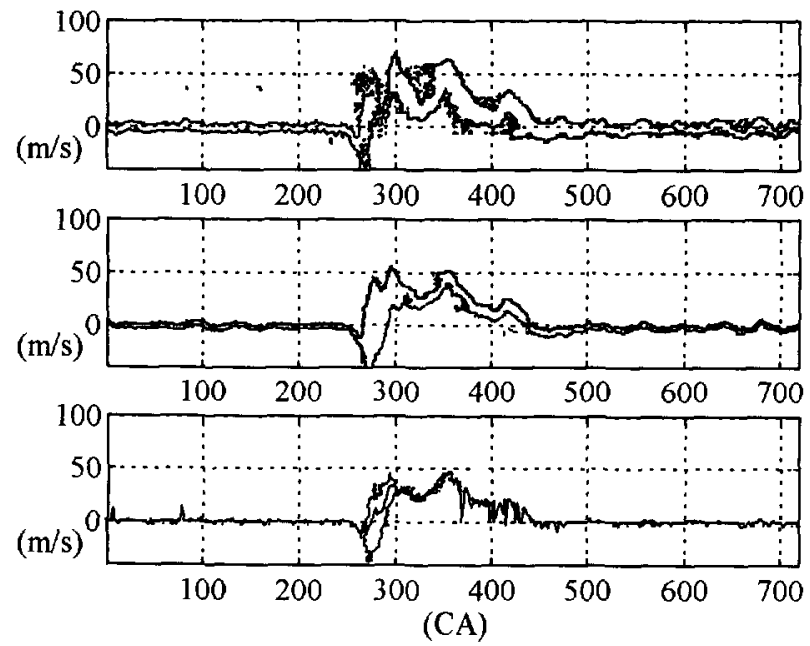

Fig. 11. - Contours of gaseous velocity for three loads $(300,600$, and $900 \mathrm{mbar}, 1400 \mathrm{rpm})$.

means that for constant amounts of aur and fuel, the evolution of air-fuel mixture concentrations during periods lasting several engine cycles, will depend on liquid film behavior

The fuel mass is fixed by the engine controller in order to mix stoichiometric quantities of air and fuel. If so, equivalence ratio equals one. During transients, the delayed response of liquid film will result on a temporary gap between fuel and air concentrations. When the air mass increases (acceleration) the equivalence ratio will be less than one because fuel will lack while film fills. On the contrary, when air mass decreases (deceleration) the equivalence ratio will be superior to unity because too much fuel will be present until film empties.

Figure 17 shows the evolution of manifold pressure and equivalence ratio on engine during transient operation (two acceleration-deceleration). We have produced also the equivalence 


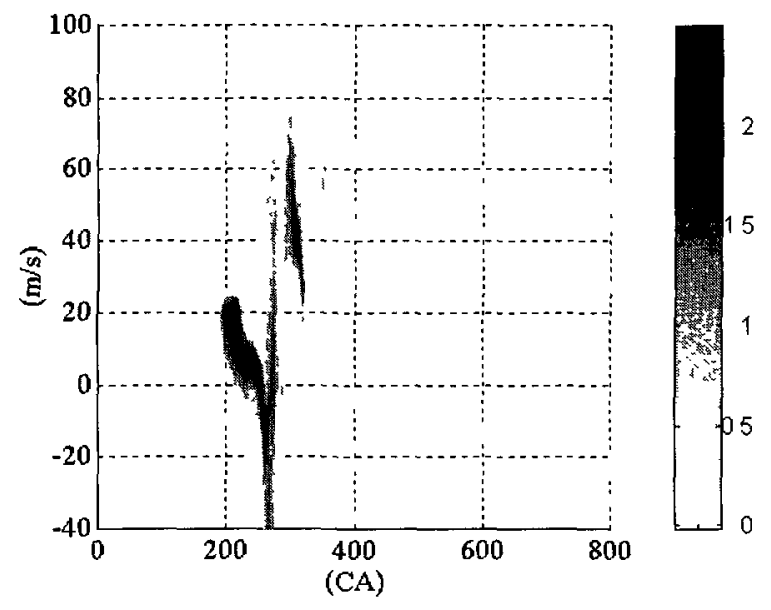

Fig 12. - Velocity of fuel droplets - (Log of the number of validated partıcles with injection, 300 mbar, $25 \%$ load, $1400 \mathrm{rpm})$.

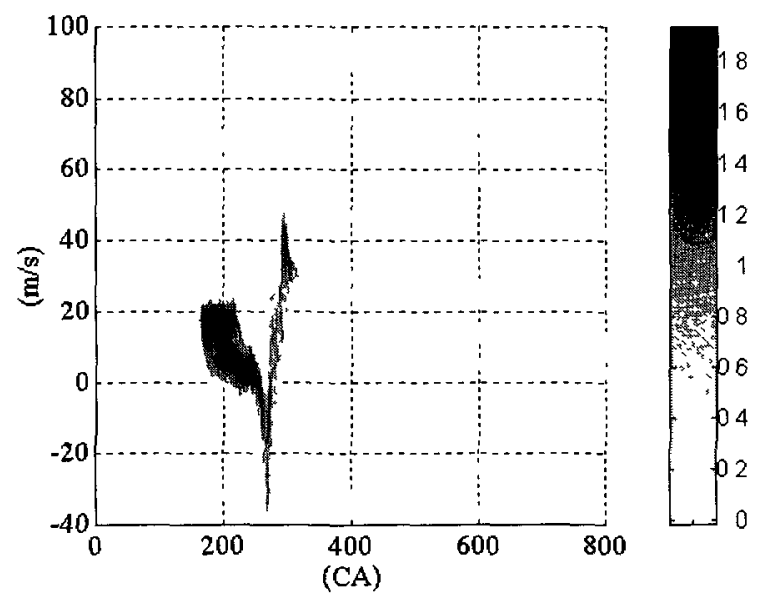

Fig 13. - Velocity of fuel droplets - (Log of the number of validated particles with injection, $600 \mathrm{mbar}$, $50 \%$ load, $1400 \mathrm{rpm}$ ).

ratio preview of the model, which is obtained by calculating the balance of different masses of each phase entering the cylinder during several engine cycles.

The good prediction by the model of local measurements depends only on the pertinence of the model equations and correlations given by literature. Whereas the modeled film depends on the atomization statistical distributions and the shape of the wetted area. Different authors that have worked on the subject as Senda [4] and Greiner [5], achieved measurements related to the atomization distributions we have adopted. The wetted area shape in model is deduced from the observation of the real shape of the deposit when engine is stopped. 

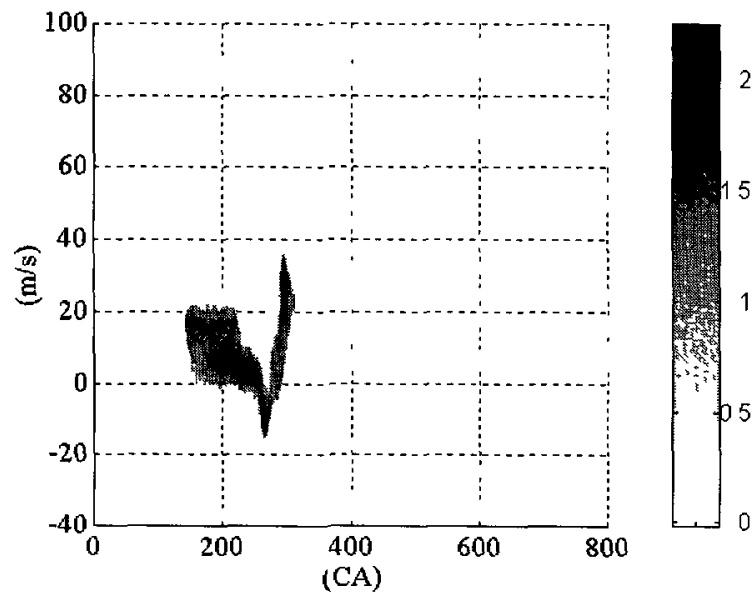

Fig 14. - Velocity of fuel droplets - (Log of the number of validated particles with injection, $900 \mathrm{mbar}$, $85 \%$ load, $1400 \mathrm{rpm}$ )

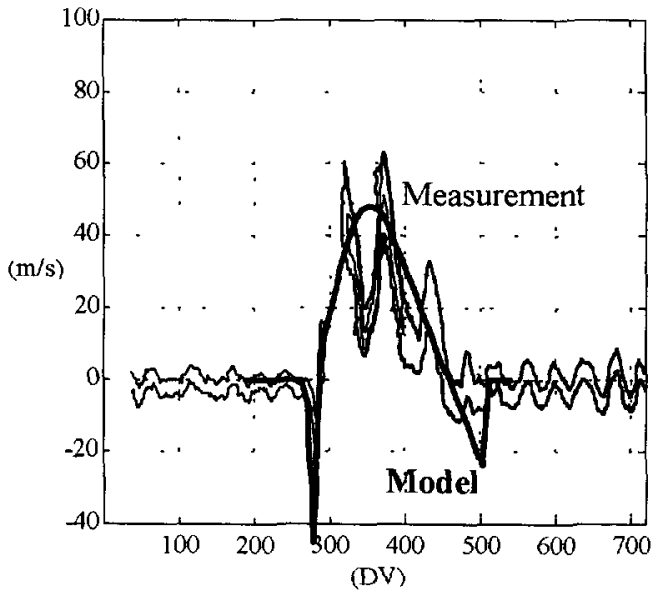

Fig. 15. - Gas velocity - Comparison of measurement contour and model result (0.3 bar, $1400 \mathrm{rpm})$.

\section{Conclusion}

We have shown that a simple physical model can describe effectively the global behavior of several phases flowing at the intake of port-injected spark ignition engines, for control purposes. During the engine cycle, it is then possible to predict the values of physical characteristics of each phase at the intake as a function of time and space. Also, the air-fuel mass balance can be predicted for several consecutive engine cycles during transients. More complex models have been presented before by other authors which give better descriptions of flows by taking into account full 3D geometry and complex phenomena like secondary atomization of droplets on film. These models can precisely describe local behavior of every phase of mixture but have almost no way to be validated by measurements on real engine. Also, they can not be applied often to industrial purposes because they need very important computer power and time. 


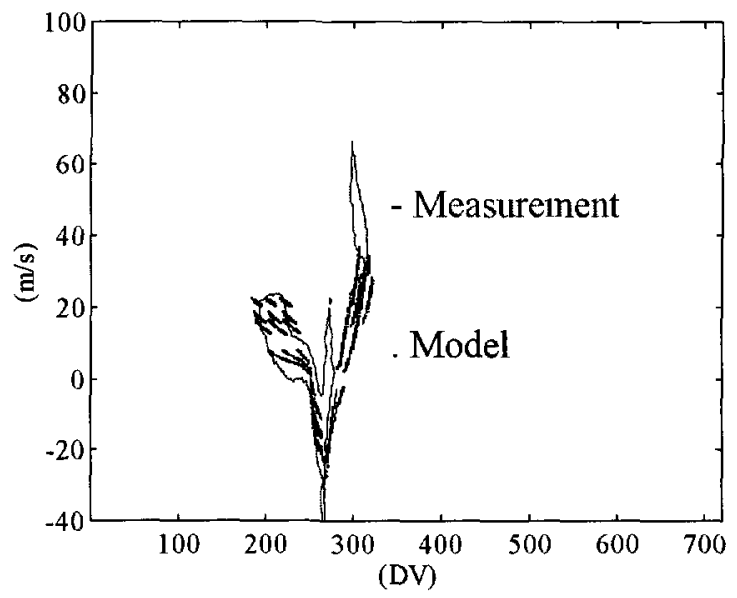

Fig. 16. - Droplets velocity - Comparison of measurement contour and model result (0.3 bar, $14000 \mathrm{rpm}$ )
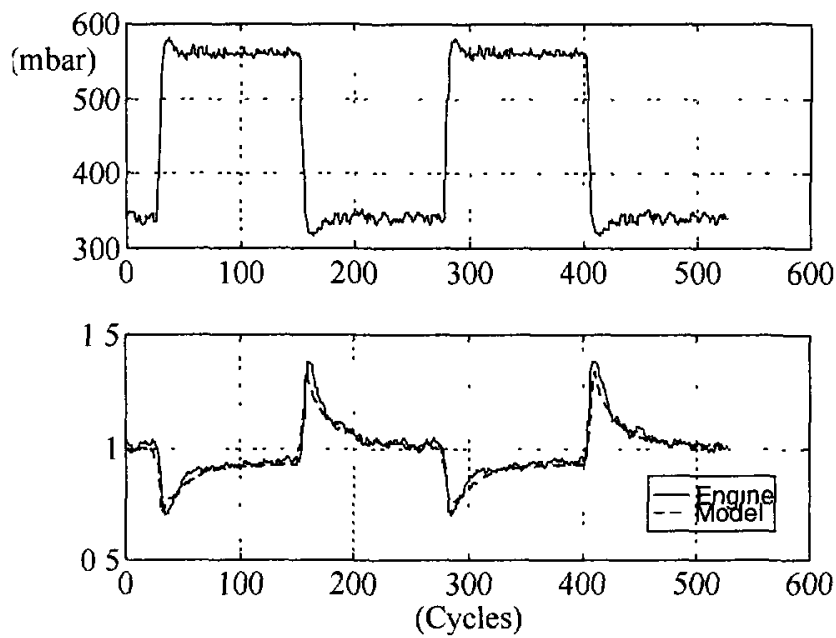

Fig 17. - Manifold pressure and equivalence ratio at the exhaust (coolant temperature: $40{ }^{\circ} \mathrm{C}$, engine speed $2000 \mathrm{rpm}$ ).

The results of the model presented here have been compared to measurements in the mtake port of engine. They correctly predicted velocities of gas and droplets and global equivalence ratio for certain conditions. But no specific measurement could be made on liquid film. Moreover, results do not apply to the mixture in the cylinder, where combustion takes place.

The validity domain of model must still be explored. For instance, the simplifying hypothesis made for this study will not hold for abnormal functioning conditions such as the very beginning of start up when fuel film is not yet established. Also, when vaporization affects the air characteristics, droplets behavior will be modified. A more complex model taking into account diffusion of hot gases during back flow should also be done. But for the engine conditions where mixture control is most needed (cold engine), the model seems to correctly predict the 
behavior of the different phases. It has been used successfully to obtain control strategies that keep constant equivalence ratio during transients (see [6]).

Nevertheless, modeling depends on several given parameters. Particularly, atomizing characteristics can only be obtained experimentally and model results are very sensitive to them. Their values have been studied by several authors but there is a lack of theoretical knowledge. Another important parameter for model is the wetted area shape, which is given by empirical observation of real wetting. So, it seems relevant to achieve a physical modeling of atomization and get the complete shape of the deposited film by a tridimensional model. Also, precise measurements of the film must be carried on experimental rigs where instruments can be easily installed. The relative importance of other phenomena that were neglected such as secondary atomization, momentum transfer from droplets to film, boiling and surface effects should be quantified.

\section{Acknowledgments}

Authors wish to thank RENAULT S.A. for their financial support.

\section{References}

[1] Aquino Ch. F., Transient A/F control characteristics of the 5 liter central fuel injection engine, SAE technical paper series 810494 (1981).

[2] Sasayama T., An advanced computer control engine system employing new combustion monitoring sensors, SAE technical paper series 865077 (1986).

[3] Heywood J.B., Internal combustion engines fundamentals, (Mc-Graw Hill Editions 1987)

[4] Senda J, Nishikori T., Tsukamoto T. and Fujimoto H., Atomization of spray under lowpressure field from pintle type gasoline injector, SAE technical paper series 920382 (1992).

[5] Greiner M., Romman P. and Steinbrenner U., Bosch fuel injectors, New developments, SAE technical paper series 870124 (1987).

[6] Le Moyne L. and Maroteaux F., Air-Fuel flow modeling applied to the reduction of air-fuel ratio excursions on port injected spark ignition engines, SAE technical paper series 970513 (1997). 